\title{
Grazing by sheep Ovis aries reduces island populations of water voles Arvicola amphibius
}

\author{
Karl Frafjord
}

Frafjord K. 2014. Grazing by sheep Ovis aries reduces island populations of water voles Arvicola amphibius. Fauna norvegica 34: 79-81.

The population of water voles Arvicola amphibius was surveyed on 21 islands in the Solvær archipelago, northern Norway, in August 2012; 11 islands with semi-wild domestic sheep Ovis aries and 10 islands without sheep. Signs from water voles are very easy to detect and were used as a measure of the population (on a scale $0-10$ ), and the numbers of sheep were counted. The ranking of signs on islands with and without sheep was compared, and a significant difference was found. Islands with sheep had, with one exception, only very small and fragmented populations of water voles, the one exception being a fairly large Carex swamp that was not grazed by the sheep and where a moderate-sized population of voles was found. Islands without sheep had much larger populations of water voles, giving a ranking about four times higher. One reason for the devastating effect of sheep on water voles is probably the fact that the sheep are living year-round on these islands with no supplemental food.

doi: 10.5324/fn.v34i0.1673. Recieved: 2014-07-03. Accepted: 2014-10-06. Published online: 2014-12-19. ISSN: 1502-4873 (printed), $1891-5396$ (electronic).

Keywords: competition, ecosystem, grazing, islands, sheep, water voles

1. Tromsø University Museum, UiT The Arctic University of Norway, P.O. Box 6050 Langnes, NO-9037 Tromsø, Norway

E-mail: karl.frafjord@uit.no

\section{INTRODUCTION}

Grazing may have profound effects on various ecosystems (i.e. Johnston \& Anthony 2008; Samelius \& Alisauskas 2009; Buesching et al. 2011). Intensive grazing may reduce layers of vegetation as well as inducing plants to strengthen their defenses either structurally or chemically (Rosenthal \& Janzen 1979; Soininen et al. 2013). Several studies report negative impacts of grazing by domestic animals on populations of small rodents (Smit et al. 2001; Klaus 2003; Steen et al. 2005; Bakker et al. 2009; Bueno et al. 2012), whereas others did not find such impact (Austrheim et al. 2008; Saetnan et al. 2012). Small rodents may be affected in many ways; loss of protective cover may expose them both to predators and inclement weather, loss of food species (both quantitatively and qualitatively), loss of nesting sites, destruction of underground runways, impacted soil making digging more difficult, and negative effects of copious amounts of faeces and urine. Grazing has also been shown to negatively affect populations of predators (Amar et al. 2011; Villar et al. 2013).

There was once a particularly dense population of eagle owl (Bubo bubo Linnaeus, 1758) in the Solvær archipelago, on the coast of Nordland County, northern Norway $\left(66^{\circ} 22^{\prime} \mathrm{N}\right.$, $12^{\circ} 36^{\prime} \mathrm{E}$ ) with a large population of water voles (Arvicola amphibius Linnaeus, 1758) as its food base (in owl pellets: 89.5 
$\%$ water voles ( $\mathrm{n}=2199$ individuals), $10.5 \%$ birds, plus a few other prey that would only have made an insignificant change in the proportions, unpublished data, see Frafjord (2003) with a much smaller sample size). Water voles are the only small mammal in Solvær, while the eagle owl is red-listed in Norway with concerns about its future. In recent years, increased numbers of semi-wild domestic sheep (Ovis aries Linnaeus, 1758) have been grazing in Solvær, mainly of an ancient, smaller Norwegian breed that stays outside all winter without supplemental food. Concerns about the impact of sheep on the population of water voles and hence on the population of eagle owls led to this preliminary investigation. Because water voles are susceptible to farming and grazing regimes (Morilhat et al. 2007; Macpherson \& Bright 2011), I predicted that sheep will to some extent reduce their populations.

\section{MATERIAL AND METHODS}

The Solvær archipelago consists of a number of larger and smaller islands and islets. This study was made in the central part of the archipelago, encompassing about $32 \mathrm{~km}^{2}$ (including both sea and land masses). Sheep are only put out on islands above a certain size, and hence on all the larger and many of the medium-sized islands. I surveyed and compared 11 islands with sheep and 10 islands without sheep with regard to the population of water voles. The status of water voles was estimated from signs (it was not feasible to trap on that many islands); holes, runways, scats and food remains, on a scale index 0-10 (sensu Giraudoux et al. 1995). Whether the remains were fresh from the current summer or old from previous years was noted. The survey was based on ten years of experience of trapping water voles to estimate their abundance, and the species is very easy to locate by signs as they are continuously digging (except in winter time). Four indices were estimated from two variables; 1) all over the island: both old and fresh signs, 2) all over the island: only fresh signs, 3) the best site for water voles on the island: both old and fresh signs, and 4) the best site on the island: only fresh signs. Because of the clumped distribution of water voles, it may be easier to compare indices from the sites with highest densities than to compare "average" indices for the whole islands. Highest vole density is found in formerly managed fields, which, although only small in extent, still exist on a number of the islands. This is also preferred foraging habitat for sheep.

The survey was made by walking slowly around the islands during August 7-12, 2012, covering 3-4 islands per day. A single transect covered a very large part of each island, as most islands are narrow. Habitats where water voles were more likely to be found (i.e., habitats with more grasses and sedges and less heather) were crisscrossed more extensively. Of the largest island only a part was surveyed $(2.1$ of $5.4 \mathrm{~km})$, the none-forested part. All other islands surveyed except two were tree-less, the two had only smaller stands of trees. The number of sheep seen (including lambs) was counted. Grazing intensity depends on area, vegetation, number of sheep and how long they have been on the island, here I only consider the number of sheep and size of islands. The area covered by each island was roughly estimated from maps on the web-site http/:sww. norgeskart.no, using the area tool after zooming in. The same herd of sheep may use several islands (crossing on low tide), for which the same number was used. On one island the sheep had only been grazing for about three months (since May), this island was included in the "no sheep" group.

\section{RESULTS AND DISCUSSION}

All islands had signs of water voles, although I was unable to find fresh signs on one of them. A dramatic reduction in signs of water voles was found on islands with sheep. For the whole island, mean ranking $( \pm 1 \mathrm{SD})$ of fresh \& old signs was $1.09 \pm 0.3$ and of fresh signs $0.64 \pm 0.5$ on islands with sheep. On islands without sheep the rankings were $4.60 \pm 1.3$ and $3.60 \pm 1.3$, respectively (sheep vs. no sheep, for both rankings: MannWhitney $\mathrm{U}=0, \mathrm{p}<0.001)$.

Similar rankings were found for the best site. On islands with sheep the rankings were $1.36 \pm 0.9$ for fresh \& old signs and $0.91 \pm 0.7$ for fresh signs. On islands without sheep the rankings were $6.20 \pm 2.2$ and $4.89 \pm 2.0$, respectively ( $U=1.5$ for fresh \& old signs and $\mathrm{U}=0$ for fresh signs, for both $\mathrm{p}<0.001)$. The number of sheep on the islands explained a very large part of the variation in the ranking index (Figure 1). All except one island with sheep got a very poor ranking, far below all islands without sheep. On the one island with sheep that attained a better ranking, equal to the minimum ranking for islands with no sheep (Figure 1), the water voles lived in a swamp with mostly Carex sp. that was not grazed by the sheep. The relatively large extent of this swamp

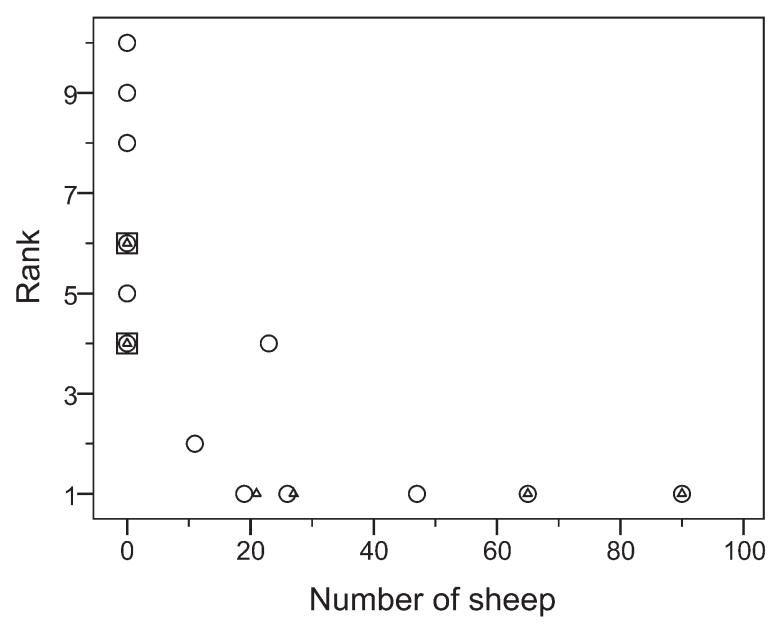

Figure I. Number of sheep plotted against ranking based on both old and fresh signs of water voles in the best site of the islands, Solvær, August 2012. Overlapping symbols have been replaced by symbols of different types and sizes. 
(about $0.031 \mathrm{~km}^{2}$ ) made this situation special, on the rest of the island only very few signs of voles were found. The sheep may have avoided Carex due to its coarse leaves, the wet conditions or the large tussocks there impeding walking. Islands with sheep were larger than those without sheep, on average $0.681 \pm 0.92$ vs. $0.122 \pm 0.07 \mathrm{~km}^{2}(\mathrm{U}=14, \mathrm{p}<0.01)$. The density of sheep varied much and the mean $132 \pm 141$ sheep $/ \mathrm{km}^{2}$ is indeed a very rough estimate. Plotting density against rank gave an even steeper downward trend than can be seen in Figure 1.

The hypothesis that grazing sheep negatively affects the population of water voles was strongly supported. Nearly all islands with sheep had only tiny and fragmented populations of voles. Here, some patches, especially the grass fields, were as heavily cropped as a lawn, and were almost devoid of voles except in marginal edges. The smallest island surveyed $(629 \mathrm{~m}$ long), tiny and with no grass field but also with no sheep, may have housed more voles than a neighbouring, much larger island (2.2 km long) with sheep. The negative relationship between water voles and sheep was unusually strong, as it is often difficult to find such correlations in ecosystems with multiple interacting factors. The presence of sheep is likely to explain most of the impact found. When the pasture is over-exploited the sheep often are moved to a different island, but it was not possible to account for the length of time sheep had grazed or the effects on the vegetation, which may explain why rank did not follow density of sheep more gradually.

The population of water voles on all islands grazed by sheep was probably too small and fragmented to substantially support eagle owl breeding. Grazing must also affect other fauna and flora (sensu Amar et al. 2011), although, on the other hand, sheep may reduce invasive plant species such as the meadowsweet Filipendula ulmaria that is hardly eaten by water voles. This impact is accentuated because the sheep consume the islands' vegetation all year round. The results indicate that reductions in sheep numbers are likely to prove beneficial for water voles and hence, their main predator in Solvær, the eagle owl. The implications of sheep grazing on the whole biodiversity in the archipelago should be of great concern.

\section{ACKNOWLEDGEMENTS}

This project was funded entirely by the County Governor of Nordland, shifting me from one island to the next was efficiently executed by Frode Johansen, and Rob Barrett greatly improved the spelling.

\section{REFERENCES}

Amar A, Davies J, Meek E, Williams J, Knight A, Redpath S. 2011. Long-term impact of changes in sheep Ovis aries densities on the breeding output of the hen harrier Circus cyaneus. Journal of Applied Ecology 48: 220-227.
Austrheim G, Mysterud A, Pedersen B, Halvorsen R, Hassel K, Evju M. 2008. Large scale experimental effects of three levels of sheep densities on an alpine ecosystem. Oikos: 117: 837-846.

Bakker ES, Olff H, Gleichman JM. 2009. Contrasting effects of large herbivore grazing on smaller herbivores. Basic and Applied Ecology 10: 141-150.

Bueno C, Ruckstuhl KE, Arigo N, Aviaz AN, Neuhaus P. 2012. Impacts of cattle grazing on small-rodent communities: an experimental case study. Canadian Journal of Zoology 90: 22-30.

Buesching CD, Newman C, Jones JT, Macdonald DW. 2011. Testing the effects of deer grazing on two woodland rodents, bank voles and woodmice. Basic and Applied Ecology 12: 207214.

Frafjord K. 2003. Do eagle owls select larger water voles? Fauna norvegica 23: 42-47.

Giraudoux P, Pradier B, Delattre P, Peblay S, Salvi D, Defaut R. 1995. Estimation of water vole abundance by using surface indices. Acta Theriologica 40: 77-96.

Johnston AN, Anthony RG. 2008. Small-mammal microhabitat associations and response to grazing in Oregon. Journal of Wildlife Management 72: 1736-1746.

Klaus M. 2003. The status, habitat, and response to grazing of water vole populations in the Big Horn Mountains of Wyoming, U.S.A. Arctic, Antarctic, and Alpine Research 35: 100-109.

MacPherson JL, Bright PW. 2011. Metapopulation dynamics and a landscape approach to conservation of lowland water voles (Arvicola amphibius). Landscape Ecology 26: 1395-1404.

Morilhat C, Bernard N, Bournais C, Meyer C, Lamboley C , Giraudoux P. 2007. Responses of Arvicola terrestris scherman populations to agricultural practices, and to Talpa europaea abundance in eastern France. Agriculture, Ecosystems \& Environment 122: 392-398.

Rosenthal GA, Janzen DH. 1979. Herbivores: their interaction with secondary plant metabolites. New York. Academic Press.

Saetnan ER, Skarpe C, Batzli GO. 2012. Do sheep affect vole populations in alpine meadows in central Norway? Journal of Mammalogy 93: 1283-1291.

Samelius G, Alisauskas RT. 2009. Habitat alteration by geese at a large arctic goose colony: consequences for lemmings and voles. Canadian Journal of Zoology 87: 95-101.

Smit R, Bokdam J, den Ouden J, Olff H, Schot-Opschoor H, Schrijvers M. 2001. Effects of introduction and exclusion of large herbivores on small rodent communities. Plant Ecology 155: 119-127.

Soininen EM, Bråthen KA, Jusdado JGH, Reidinger S, Hartley SE. 2013. More than herbivory: levels of silica-based defences in grasses vary with plant species, genotype and location. Oikos 122: $30-41$

Steen H, Mysterud A, Austrheim G. 2005. Sheep grazing and rodent populations: evidence of negative interactions from a landscape scale experiment. Oecologia 143: 357-364.

Villar N, Lambin X, Evans D, Pakeman R, Redpath S. 2013. Experimental evidence that livestock grazing intensity affects the activity of a generalist predator. Acta Oecologia 49: 12-16.

Editorial responsibility: Torkild Bakken.

This article is open-access and distributed under the terms of the Creative Commons Attribution-Noncommercial 3.0 Unported License (http://creativecommons.org/licenses/by-nc/3.0/). This permits all non-commercial use, distribution, and reproduction in any medium, provided the original work is properly cited. 